\title{
Comparison of penetrating thoracic traumas in patients with gunshot and stab wounds in an emergency department
}

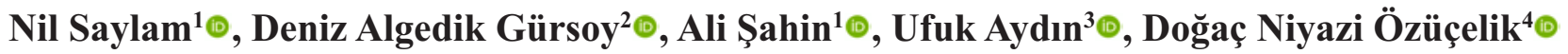 \\ ${ }^{1}$ Department of Emergency Medicine, Şırnak State Hospital, Şırnak, Turkey \\ ${ }^{2}$ Department of Emergency Medicine, Yeditepe University School of Medicine, İstanbul, Turkey \\ ${ }^{3}$ Department of Cardiovascular Surgery, University of Helath Sciences, Bursa Yüksek İhtisas Training and Research Hospital, Bursa, \\ Turkey \\ ${ }^{4}$ Department of Emergency Medicine, Kanuni Sultan Süleyman Training and Research Hospital, İstanbul, Turkey
}

\begin{abstract}
Objectives: Thoracic trauma is among the most important causes of mortality in emergency departments. In this study of penetrating stab wounds (PSWs) and gunshot wounds (GSWs) admitted to the emergency department with penetrating thoracic trauma cases clinical findings, emergency treatment approaches and survivals were compared with literature information.

Methods: One hundred fifty-two patients who applied to Bakırköy Dr. Sadi Konuk Training and Research Hospital Emergency Department with penetrating thoracic trauma on 1 January 2014 and 31 December 2014 were evaluated retrospectively the patients. SPSS 22.0, NY, USA program was used in the analyzes.

Results: Patients administered with PSW were $79.6 \%$, with GSW were $20.4 \%$. Patients in the group GSW were admitted to the emergency department with more serious symptoms than patients in the group PSW (Triage level 2, GSW: 87.1\%, PSW: 62.8\% and Triage level 3, GSW: $12.9 \%$ vs. PSW: $37.2 \%),(p=0.010)$. Hemothorax $(25.8 \%)$ in PSW patients and pneumothorax $(40.5 \%)$ in GSW patients was detected more frequently. Surgical treatment was performed in 14.9\% of patients with PSW, tube thoracostomy was performed in $24 \%$, and $62.82 \%$ were treated with conservative treatment. Surgical treatment was performed in $35.5 \%$ of GSW patients and tube thoracostomy was performed in $29 \%$, and $48.4 \%$ were treated with conservative treatment $(p>0.05)$.

Conclusion: Despite the lower incidence of GSW than PSW in emergency departments, GSW require more surgical intervention and have a higher mortality rate.

Keywords: thoracic trauma, emergency, triage, mortality, penetrating
\end{abstract}

$\mathrm{T}$ raumas are among the most important health problems causing mortality and morbidity in the world. Thoracic injuries account for one third of the cases hospitalized with trauma and about $20-25 \%$ of traumatic deaths are reported to be due to thoracic trauma [1]. Despite the fact that approximately $70 \%$ of thoracic traumas are due to blunt trauma, an important cause of morbidity and mortality is penetrant traumas [2-4]. Most of the patients with thoracic trauma are treated conservatively [5]. Less than $10 \%$ of blunt

Received: July 31, 2018; Accepted: January 15, 2019; Published Online: February 4, 2019

How to cite this article: Saylam N, Algedik Gürsoy D, Şahin A, Aydın U, Özüçelik DN. Comparison of penetrating thoracic traumas in patients with gunshot and stab wounds in an emergency department. Eur Res J 2020;6(1):1-6. DOI: 10.18621/eurj.449806

Address for correspondence: Nil Saylam, MD., Şırnak State Hospital, Department of Emergency, Şırnak, Turkey E-mail: nil-saylam@hotmail.com 
chest injuries and only $15 \%$ to $30 \%$ of penetrating chest injuries require operative intervention (typically thoracoscopy or thoracotomy) [6]. In penetrating thoracic trauma penetrating stab wound (PSW) is still higher than gunshot wound (GSW) although PSW/ GSW ratio varies from country by country $[7,8]$. Mortality in penetrating thoracic trauma is higher in GSW [7].

In this study, clinical findings of the cases, emergency treatment approaches and survival in emergency department were retrospectively investigated and compared with the literature information in the patients who applied to the emergency department with the cause of penetrating thoracic trauma (PSW and GSW).

\section{METHODS}

The study was carried out retrospectively between 01.01.2014 and 31.12.2014 among the patients who applied to Bakırköy Dr.Sadi Konuk Training and Research Hospital Emergency Medical Clinic. Within a year, a total of 158 patient file penetrating thoracic trauma (PSW and GSW) has been reached. Six patients with missing file information were excluded from the study.

The gender of the patients, vital signs, in-hospital emergency triage, thoracic pathologies, injury type, location of injuries, trauma scores, treatment methods, duration of emergency department stay, and mortality rates were evaluate.

This study was approved by the Bakırköy Dr. Sadi Konuk Training and Research Hospital Ethic Committee.

\section{Statistical Analysis}

Mean, standard deviation, median lowest, highest, frequency and ratio values were used in the descriptive statistics of the data. The distribution of the variables is measured by the Kolmogorov Smirnov test. MannWhitney $U$ test was used in the analysis of quantitative data. Chi-square test was used to analyze qualitative data, and Fischer test was used when chi-square test conditions were not met. SPSS 22.0, NY, USA program was used in the analyzes.

\section{RESULTS}

The age range of the patients was between 15 and 69 years (mean age: $31 \pm 11.6$ years). Of the 152 patients who were evaluated, one hundred twenty-one were admitted to the emergency department due to PSW and thirty-one of the GSW. There was a male predominance in both groups; $95.9 \%$ of PSW patients, $90.3 \%$ of GSW $(p=0.207)$. Gender distribution, injury characteristics, treatment, hospital stay, and mortality rates of both groups are summarized in Table 1.

The vital findings of the patients are summarized in Table 2. When the vital signs of both groups were examined, the number of pulses per minute was lower in PSWs $(85.8 \pm 13.5$ / min for PSW, $91.9 \pm 14.9 / \mathrm{min}$ for GSW, $p=0.012$ ). Percentage of oxygen saturation was higher in PSW group (95.2 \pm 9.2 in PSW, $93.8 \pm$ 4.9 in GSW, $p=0.004)$.

Triage severity scores of all penetrating thoracic trauma patients were evaluated in the 2 and 3 categories according to the five-level triage system (67.2\% were Triage 2 and $32.8 \%$ were Triage 3 ). Patients in the GSW group had a more severe triage score (Triage 2; GSW: 87.1\%, PSW: 62.8\%), (Triage 3, GSW: $12.9 \%$, PSW: $37.2 \%),(p=0.010)$ than the patients in the PSW group.

In PSW group hemothorax (25.8\%) was found and in GSW group pneumothorax was detected more (40.5\%). In GSW group, the rates of injury to the right thoracic anterior $(32.5 \%)$ and right thoracic posterior wall $(32.3 \%)$ were higher than those in the PSW group ( $p=0.05$ and $p=0.036$, respectively). When both groups were assessed within themselves, there was no difference in injury location in the GSW group, whereas the most injured location in the PSW group was the left thoracic anterior wall (47.1\%).

Both Glascow Coma Score (GCS) and Triage Revised Trauma Score (TRTS) were higher in PSW group than in GSW group (GCS $14.7 \pm 1.6$ and $13.6 \pm$ 3.6 , TRTS $11.7 \pm 1.6$ and $10.7 \pm 3.6$, respectively) $(p$ $=0.007$ and $p=0.008$, respectively).

Of the patients admitted due to PSW; cardiopulmonary resuscitation (CPR) was performed in $3(2.5 \%)$ patients, tube thoracostomy in 29 patients $(24 \%)$, mechanical ventilation in $7(5.8 \%)$ patients, 
Table 1. Characteristics of the patients

\begin{tabular}{|c|c|c|c|c|}
\hline & & $\begin{array}{c}\text { PSW } \\
(n=121)\end{array}$ & $\begin{array}{c}\text { GSW } \\
(\mathbf{n}=\mathbf{3 1})\end{array}$ & $p$ value \\
\hline \multirow[t]{2}{*}{ Gender } & Female & $5(4.1 \%)$ & $3(9.7 \%)$ & 0.207 \\
\hline & Male & $116(95.9 \%)$ & $28(90.3 \%)$ & \\
\hline \multirow[t]{2}{*}{ Triage Level } & Triage 2 & $76(62.8 \%)$ & $27(87.1 \%)$ & 0.010 \\
\hline & Triage 3 & $45(37.2 \%)$ & $4(12.9 \%)$ & \\
\hline \multirow[t]{4}{*}{ Injury area } & Right tx anterior wall & $20(16.5 \%)$ & $10(32.5 \%)$ & 0.050 \\
\hline & Left tx anterior wall & $57(47.1 \%)$ & $11(35.5 \%)$ & 0.246 \\
\hline & Right tx posterior wall & $19(15.7 \%)$ & $10(32.3 \%)$ & 0.036 \\
\hline & Left tx posterior wall & $36(29.8 \%)$ & $12(38.7 \%)$ & 0.338 \\
\hline \multirow[t]{5}{*}{ Type of injury } & Pneumothorax & $9(29 \%)$ & $49(40.5 \%)$ & 0.241 \\
\hline & Hemothorax & $8(25.8 \%)$ & $22(18.2 \%)$ & 0.341 \\
\hline & Lung contusion & $5(16.1 \%)$ & $14(11.6 \%)$ & 0.493 \\
\hline & Rib fracture & $4(12.9 \%)$ & $17(14 \%)$ & 0.869 \\
\hline & Pneumomediastinum & $3(9.7 \%)$ & $15(12.4 \%)$ & 0.676 \\
\hline \multirow{2}{*}{$\begin{array}{l}\text { In the emergency Tube } \\
\text { Thoracostomy }\end{array}$} & Yes & $29(24 \%)$ & $9(29 \%)$ & 0.561 \\
\hline & No & $92(76 \%)$ & $22(71 \%)$ & \\
\hline \multirow{2}{*}{$\begin{array}{l}\text { In the emergency } \\
\text { Mechanical Ventilation }\end{array}$} & Yes & $7(5.8 \%)$ & $4(12.9 \%)$ & 0.172 \\
\hline & No & $114(94.2)$ & $27(87.1)$ & \\
\hline \multirow[t]{2}{*}{ Mortality } & Yes & $4(3.3 \%)$ & $4(12.9 \%)$ & 0.033 \\
\hline & No & 117 (96.7\%) & $27(87.1 \%)$ & \\
\hline
\end{tabular}

PSW $=$ Penetrating Stab Wound GSW $=$ Gunshot Wound, $\mathrm{Tx}=$ Thorax

surgical treatment in $18(14.9 \%)$ patients, conservative treatment in $76(62.8 \%)$ patients. Of the patients admitted due to GSW; cardiopulmonary resuscitation (CPR) was performed in $2(6.4 \%)$ patients, tube thoracostomy in $9(29 \%)$ patients, mechanical ventilation in $4(12.9 \%)$ patients, surgical treatment in $11(35.5 \%)$ patients, conservative treatment in 15 (48.4\%) patients. Laparoscopy was performed in 4 patients, laparotomy in 8 patients, thoracotomy in 9 patients, sternotomy in 3 patients, laminectomy in 1 patient, AV fistula ligation in 1 patient, arterial repair in 2 patients, foreign body removal in 2 patients and soft tissue repair in 1 patient. The rates of tube thoracostomy ( $24 \%$ in PSW, $29 \%$ in GSW, $p=0.561$ ) and mechanical ventilation requirement $(5.8 \%$ for PSW, $12.9 \%$ for GSW, $p=0.172$ ) were similar in both groups as treatment. Length of stay in the emergency department was $11 \pm 8.2$ hours in PSWs, and $13.6 \pm$ 
Table 2. Vital and other findings of patients

\begin{tabular}{lccc}
\hline & $\begin{array}{c}\text { PSW } \\
(\mathbf{n = 1 2 1})\end{array}$ & $\begin{array}{c}\text { GSW } \\
(\mathbf{n}=\mathbf{3 1})\end{array}$ & $\boldsymbol{p}$ value \\
\hline Systolic blood pressure (mmHg) & $114.3 \pm 12.6$ & $114.3 \pm 15.6$ & 0.870 \\
\hline Diastolic blood pressure (mmHg) & $70.3 \pm 9.4$ & $67.5 \pm 10$ & 0.160 \\
\hline Pulse (beat/min) & $85.8 \pm 13.5$ & $91.9 \pm 14.9$ & $\mathbf{0 . 0 1 2}$ \\
Oxygen saturation (\%) & $95.2 \pm 9.2$ & $93.8 \pm 4.9$ & $\mathbf{0 . 0 0 4}$ \\
\hline Respiratory rate (rate/min) & $18.2 \pm 5.7$ & $18.5 \pm 8.8$ & 0.485 \\
Glasgow Coma Score & $14.7 \pm 1.6$ & $13.6 \pm 3.6$ & $\mathbf{0 . 0 0 7}$ \\
\hline Triage Revised Trauma Score & $11.7 \pm 1.6$ & $10.7 \pm 3.6$ & $\mathbf{0 . 0 0 8}$ \\
\hline Hospital Length of Stay (days) & $11 \pm 8.2$ & $13.6 \pm 9.8$ & 0.670 \\
\hline
\end{tabular}

Data are shown as mean \pm standard deviation. $\mathrm{PSW}=$ Penetrating Stab Wound; GSW $=$ Gunshot Wound

9.8 hours in GSWs. There was no difference between the two groups in terms of length of stay in the emergency department ( $p=0.670)$ (see Table 2).

The mortality rate was higher in GSW group than in PSW group $(12.9 \%$ in GSW, $3.3 \%$ in PSW, $p=$ 0.033 ), although the number of patients who died in both GSWs and PSWs was 4. Of the eight patients who died, six patients had an isolated thoracic injury and there were also abdominal injuries accompanying the thorax in two patients.

\section{DISCUSSION}

Thoracic traumas constitute approximately onefourth of trauma-induced deaths [1, 2]. Thoracic traumas are most commonly seen in males and between the second and fifth decades [9]. In a study of 827 cases of Kong et al. [10] comparing penetrating thoracic trauma with PSW and GSW groups, $92 \%$ of the patients were male and the mean age was 24 . In our study, similarly, $94.7 \%$ of the patients who applied for penetrating thoracic trauma were male and the mean age was $31 \pm 11.6$. This can be explained by the fact that the young male population plays a more active role in social life and is more exposed to violent incidents.

In Yücel et al.'s study [11], 79.2\% of penetrating trauma patients were reported as GSW and $20.8 \%$ of them were reported as PSW. In a study of Madiba et al. [7] examining penetrating thoracic injuries, 116 GSW patients were seen, compared to 473 PSW patients. In our study, the rate of application for PSW was higher. While these rates vary from country to country in studies, they vary according to the characteristics of the hospital (military hospital, trauma hospital, etc). Due to increased civilian armament rates and terrorist incidents; the increase in the number of patients who are injured by gunshot wounds in the studies conducted is remarkable.

Triage guidelines classify emergency patients into various categories and associate them with the maximum waiting period based on specific clinical emergency criteria. Studies have shown that five-level triage systems are more effective, valid, and reliable $[12,13]$. There were no studies about the triage and triage levels of emergency penetrating thoracic trauma and diagnosis and treatment processes. The reason for this may be thatthe studies were performedone by chest surgeons and trauma surgeons in general. Five emergency triage system is applied in the emergency department of our hospital. In this study, there a significant difference in the mortality and treatment duration according to the triage 3 level of the patients diagnosed and treated with triage 2 level and the diagnosis and treatment of the patients with thorax 
injuries. Patients in the GSW group had a more severe triage score than the PSW group. It was determined that patients with acute thoracic trauma due to GSW should be evaluated at least triage 2 level in the emergency departments and close follow-up and treatment is required as GSW caused more morbidity and mortality than PSW patients.

The most common intrathoracic complications in thoracic trauma are hemothorax, pneumothorax and hemopneumothorax $[9,11]$. In the study of Madiba et al., [7] hemothorax rates were similar in PSW and GSW groups, but the rate of pneumothorax was higher in patients admitted due to PSW. In the study of Kong et al., [10] the rate of pneumothorax was higher in the PSW group, whereas the rate of hemopneumothorax was higher in the GSW group. In our study, hemothorax rate was higher in PSW group, pneumothorax rate was higher in GSW group. In another study conducted in our country, low systolic blood pressure during hospitalization was found to be important for mortality and morbidity [14]. In Hasbahçeci et al's study [15], low systolic blood pressure and apneic breathing were found to be effective on mortality. In our study; the relationship between mortality, high pulse rate and low oxygen saturation is remarkable in GSW patients with high mortality rates.

It is known that trauma scoring systems are especially important in standardizing trauma severity and predicting prognosis [16, 17]. Eftekhar et al. [18] and Champion et al. [19] argue that Revised Trauma Score is a predictor of mortality in trauma patients. In the study of Emircan et al., [16] Glasgow Coma Score and Revised Trauma Score of patients with mortality were found to be lower than those of living patients. In our study, GCS and TRTS were lower in GSW group. Glasgow Coma Score and Triage Revised Trauma Score values used in our study were found to be significantly associated with mortality formation in direct proportion to the prevalence and severity of the trauma present in the patient; the importance of using trauma scoring systems in the evaluation of trauma patients.

Conservative approaches without thoracic surgery are often enough in the treatment of thoracic trauma $[10,20]$. In particular, it is possible to treat isolated thoracic trauma effectively without surgery and, if necessary, with tube thoracostomy $[20,21]$. In the study of 1142 cases where trauma patients were evaluated, $601(52 \%)$ patients received tube thoracostomy, $38(3.3 \%)$ patient thoracotomy and 503 (44\%) patients received conservative treatment [22]. In the study of Kong et al., [10] 96\% of the patients were operated without surgery and showed that selective conservative treatment of penetrating thoracic trauma was appropriate. In our study, conservative treatment was applied $62.8 \%$ in the PSW group and $48.4 \%$ in the GSW group. These ratios are consistent with the literature and show that a selective conservative treatment approach is appropriate for thorax trauma.

The proportion of patients with thoracic trauma requiring major surgery varies between 15 and $20 \%$ $[23,24]$. In our study, the rate of surgical intervention was $14.9 \%$ in patients with PSW and $35.5 \%$ in GSW patients. When all patients were evaluated, the rate of surgery was $19 \%$. In the studies performed, the mean hospitalization time of thoracic traumas exceeds 8 days [25]. In the study of Cakan et al., [14] this time was $9.6 \pm 8.6$ days. The duration of hospitalization in our study was similar to other studies. Approximately $25 \%$ of traumatic deaths are due to thoracic trauma [20]. Studies have shown that GSW/ PSW mortality rates are higher [7, 10]. In Clarke et al.'s study [26], the mortality rate due to GSW in penetrating thoracic trauma was 8 times higher than the mortality rate due to PSW. In our study, the mortality rate of GSW was found to be higher (consistent with the literature).

\section{CONCLUSION}

As a result; patients with GSW in emergency departments require more surgical intervention and have higher mortality although less visible than patients with PSW in emergency departments require. Implementation of in-hospital triage systems is important in terms of patient management and treatment continuity.

\section{Author contributions}

NS: study conception, data collection, analysis; DAG: data collection, analysis, manuscript revision; AŞ: data interpretation, manuscript revision; UA: data interpretation, manuscript revision; DNÖ: data interpretation, manuscript revision; All authors have 
read and approved the final manuscript.

\section{Conflict of interest}

The authors disclosed no conflict of interest during the preparation or publication of this manuscript.

\section{Financing}

The authors disclosed that they did not receive any grant during conduction or writing of this study.

\section{REFERENCES}

1. Battistella FD, Benfield JR. Blunt and penetrating injuries of the chest wall, pleura, and lungs. In: Shields TW. General Thoracic Surgery. $5^{\text {th }}$ ed. Philadelphia: Williams and Wilkins; 2000:pp. 815-63.

2. Durso AM, Caban K, Munera F. Penetrating thoracic injury. Radiol Clin North Am 2015;53:675-93.

3. Kayıhan A, Yavuz Ş, Ünal M, Sanisoğlu İ, Canik S, Eren E. [Traumatic laseration of left anterior descending artery and revascularization]. Turk Gogus Kalp Dama 1992;1:127-30. [Article in Turkish]

4. Ata Y, Türk T, Yalçın M, Selimoğlu Ö, Özyazıcıŏglu A, Yavuz Ş. [Heart Injury]. İ Ü Kardiyol Enst Derg 2009;8:16-9. [Article in Turkish]

5. Burack JH, Kandil E, Sawas A, O'Neill PA, Sclafani SJ, Lowery RC, et al. Triage and outcome of patients with mediastinal penetrating trauma. Ann Thorac Surg 2007;83:37782; discussion 382 .

6. ATLS Subcommittee; American College of Surgeons' Committee on Trauma; International ATLS working group. Advanced trauma life support $\left(\mathrm{ATLS}^{\circledR}\right)$ : the ninth edition. J Trauma Acute Care Surg 2013;74:1363-6.

7. Madiba TE, Thomson SR, Mdlalose N. Penetrating chest injuries in the firearm era. Injury 2001;32:13-6.

8. Ludwig C, Koryllos A. Management of chest trauma. J Thorac Dis 2017;9(Suppl 3):S172-S177.

9. Liman ST. Thoracic traumas. [Specialized thesis] Ankara: Ankara Chest Diseases and Thoracic Surgery Center; 1997.

10. Kong VY, Sartorius B, Clarke DL. The selective conservative management of penetrating thoracic trauma is still appropriate in the current era. Injury 2015;46:49-53.

11. Yücel O, Sapmaz E, Çaylak H, Gözübüyük A, Gürkök S, Dakak M, et al. Analysis of 748 patients with thoracic trauma requiring hospitalization. Gulhane Med J 2009;51:86-90.
12. Wuerz RC, Milne LW, Eitel DR, Travers D, Gilboy N. Reliability and validity of a new five-level triage instrument. Acad Emerg Med 2000;7:236-42.

13. Travers DA, Waller AE, Bowling JM, Flowers D, Tintinalli J. Five-level triage system more effective than three-level in tertiary emergency department. J Emerg Nurs 2002;28:395-400. 14. Cakan A, Yuncu G, Olgaç G, Alar T, Sevinç S, Ors Kaya S, et al. [Thoracic trauma: analysis of 987 cases]. Ulus Travma Derg 2001;7:236-41. [Article in Turkish]

15. Hasbahçeci M, Ozpek A, Başak M, Calışkan M, Ener BK, Alimoğlu O. [Factors affecting mortality in blunt thoracic trauma]. Ulus Travma Acil Cerrahi Derg 2013;19:127-32.

16. Emircan S, Ozgüç H, Akköse Aydın SA, Ozdemir F, Köksal O, Bulut M. Factors affecting mortality in patients with thorax trauma. Ulus Travma Acil Cerrahi Derg 2011;17:329-33.

17. Costa G, Tomassini F, Tierno SM, Venturini L, Frezza B, Cancrini $\mathrm{G}$, et al. The prognostic significance of thoracic and abdominal trauma in severe trauma patients (Injury severity score > 15). Ann Ital Chir 2010;81:171-6.

18. Eftekhar B, Zarei MR, Ghodsi M, Moezardalan K, Zargar M, Ketabchi E. Comparing logistic models based on modified GCS motor component with other prognostic tools in prediction of mortality: results of study in 7226 trauma patients. Injury 2005;36:900-4.

19. Champion HR, Sacco WJ, Copes WS, Gann DS, Gennarelli TA, Flanagan ME. A revision of the Trauma Score. J Trauma 1989;29:623-9.

20. Lema MK, Chalya PL, Mabula JB, Mahalu W. Pattern and outcome of chest injuries

at Bugando Medical Centre in Northwestern Tanzania. J Cardiothorac Surg. 2011;6:7.

21. Thomas MO, Ogunleye EO. Etiopathology and management challenges of blunt chest trauma in Nigeria. Asian Cardiovasc Thorac Ann 2009; 17:608-11.

22. Şentürk E, Doğan Y, Yoldaş E. [Chest trauma; analysis of 1142 cases]. Turk Thorac J 2010;11:47-54. [Article in Turkish]

23. Washington B, Wilson RF, Steiger Z, Bassett JS. Emergency thoracotomy: a four-year review. Ann Thorac Surg 1985;40:18891.

24. Gopinath N. Thoracic trauma. Indian J Thorac Cardiovasc Surg 2004;20:144-8.

25. Çağırıcı U, Uç H, Çalkavur T, Gürcün U, Badak İ, Bilkay Ö, et al. [Thoracic trauma: the 6-year experience]. Ulus Travma Derg 1998;4:248-52. [Article in Turkish]

26. Clarke DL, Quazi MA, Reddy K, Thomson SR. Emergency operation for penetrating thoracic trauma in a metropolitan surgical service in South Africa. J Thorac Cardiovasc Surg 2011;142:563-8. 